\title{
Effectiveness of gamma and electron beam irradiation as preserving technologies of fresh Agaricus bisporus Portobello: A comparative study
}

\author{
Rossana V.C. Cardoso ${ }^{a, b}$, Ângela Fernandes ${ }^{a}$, João C.M. Barreira ${ }^{a, *}$, Sandra Cabo Verde ${ }^{c}$, \\ Amilcar L. Antonio $^{\mathrm{a}}$, Ana M. Gonzaléz-Paramás ${ }^{\mathrm{b}}$, Lillian Barros ${ }^{\mathrm{a}}$, Isabel C.F.R. Ferreira ${ }^{\mathrm{a}, *}$ \\ ${ }^{a}$ Centrode Investigação de Montanha (CIMO), Instituto Politécnico de Bragança, Campus de Santa Apolónia, 5300-253 Bragança, Portugal \\ ${ }^{\mathrm{b}}$ Grupode Investigación en Polifenoles (GIP), Unidad de Nutrición y Bromatología, Facultad de Farmacia, Universidad de Salamanca, Campus Miguel de Unamuno \\ E-37007, Salamanca, Spain \\ ${ }^{\mathrm{c}}$ Centro de Ciências e Tecnologias Nucleares (C ${ }^{2}$ TN), Instituto Superior Técnico, Universidade de Lisboa, E.N. 10 ao km 139.7, 2695-066 Bobadela LRS, Portugal
}

\section{A R T I C L E I N F O}

\section{Keywords:}

Portobello mushrooms

Gamma irradiation

Electron beam irradiation

Chemical characterization

Ergosterol

\begin{abstract}
A B S T R A C T
Mushroom production and consumption is increasing, but high perishability still represents a major commercial drawback. Besides increasing the product shelf-life, conservation processes should be innocuous to consumers. Therefore, the effects of gamma and electron beam radiation on chemical and nutritional composition of fresh samples of Agaricus bisporus Portobello (a highly commercialized species) were assessed. Mushrooms were irradiated at 1, 2 or $5 \mathrm{kGy}$, and analyzed at different times (0, 4 and 8 days). In general, irradiation type had higher effect than irradiation dose. Gamma irradiation was associated with higher contents in sugars and ergosterol, while the $5 \mathrm{kGy}$ dose, independently of irradiation source, was linked with higher protein levels. Nonetheless, irradiation might represent an effective preservation methodology for Portobello mushrooms, as it was effective in maintaining their chemical profiles (except for minor organic acids and saturated fatty acids) throughout the assayed time intervals.
\end{abstract}

\section{Introduction}

Mushrooms have been included in the human diet for centuries, mainly because of organoleptic and nutritional characteristics, such as low lipid levels and large amounts of carbohydrates, proteins, amino acids, vitamins, phosphorus and other minerals (Reis, Martins, Vasconcelos, Morales, \& Ferreira, 2017). Besides their gastronomic relevance, mushrooms have also been reported for their pharmaceutical application, which is mainly supported by their antioxidant, antimicrobial, immunomodulating and antitumor effects (Reis et al., 2017). In recent years, the knowledge about the chemical composition and nutritional value of edible mushrooms has been increasing. Nevertheless, their high perishability, which leads to immediate quality loss after harvesting, represents a drawback for their distribution and marketing as fresh products. Therefore, it is necessary to extend the shelf life of fresh mushrooms, as this is a key factor in making any food product profitable for longer periods of time, bringing benefits to the producer and distributors (Fernandes et al., 2014a).

Besides the need of extended storage periods, there is also a general trend to develop less severe, and therefore less harmful, food preservation techniques (Fernandes et al., 2015). In this sense, there has been extensive research on finding the most suitable technology for mushroom preservation. Among the available methods to preserve food, such as sun drying, hot air and oven drying (Ma, Chen, Zhu, \& Wang, 2013), irradiation has also been applied as a decontamination technique, increasing shelf life and improving food safety. This technique is mainly intended to destroy microorganisms or insects, eliminate toxins and improve functional properties, with the least impairment in sensory and nutritional quality (Akram \& Kwon, 2010). Gamma rays are a type of electromagnetic radiation produced in nuclear decay processes. They are highly energetic, due to their high frequency and consequently low wavelength, having high penetrating capacity (Lima, 2014). Electron beam radiation, in turn, is a type of ionizing energy that is usually characterized by its low penetration and high dose rates, being generally used for thin and low-density products (Fernandes et al., 2014a). However, both technologies are suitable for post-harvest treatment, ensuring hygienic and sensory quality of mushrooms (Fernandes et al., 2014a, 2014b).

The three main mushroom species in which the effects of ionizing radiations have been studied are Agaricus bisporus (Wani, Hussain, Meena, Dar, \& Mir, 2009), Lentinus edodes (Jiang, Luo, Chen, Shen, \& Ying, 2010), and Pleurotus ostreatus (Jasinghe \& Perera, 2006), which

\footnotetext{
* Corresponding authors.

E-mail addresses: jbarreira@ipb.pt (J.C.M. Barreira), iferreira@ipb.pt (I.C.F.R. Ferreira).
} 
might be easily understood if we consider their high production worldwide. Agaricus bisporus reach an annual production around 4.4 billion kg, considering white and brown (Portobello) types (Royse, Baars, \& Tan, 2016). A. bisporus Portobello stands out for its nutritional characteristics, exceptional texture, stiff pulp, easy digestibility, characteristic taste and pleasant aroma, and culinary versatility (Raimundo \& Beraldo, 2015). This species is also a rich source of minerals, vitamins (A, C and D), ergosterol, beta-carotene, phenolic compounds, and terpenes, among other molecules with antioxidant effects and potentially positive implications in several diseases, such as cancer, rheumatoid arthritis, atherosclerosis, as well as the degenerative processes associated with aging (Teichmann, Dutta, Staffas, \& Jägerstad, 2007).

Accordingly, this work was designed to evaluate the effects of gamma and electron beam radiation on the chemical and nutritional composition of fresh Portobello commercial samples. Different radiation doses and storage times were tested, in order to verify the most suitable conditions to be applied to this particular type of food product.

\section{Materials and methods}

\subsection{Sampling and irradiation processes}

Agaricus bisporus Portobello samples (acquired in a local market in Bragança, northeast Portugal, in June 2017) were divided into four groups: control (non-irradiated, $0 \mathrm{kGy}$ ), sample 1 ( $1 \mathrm{kGy}$ ), sample 2 ( $2 \mathrm{kGy}$ ) and sample 3 ( $5 \mathrm{kGy}$ ) with eighteen specimens (approximately $200 \mathrm{~g}$ ) per group (72 mushrooms in total). The dose has been limited to $5 \mathrm{kGy}$ because higher doses could compromise mushroom integrity (particularly its texture). Each group was further divided into equal parts (9 specimens each), corresponding to each irradiation methodology.

Gamma irradiation was performed in Centro de Ciências e Tecnologias Nucleares (Instituto Superior Técnico, Universidade de Lisboa, Portugal) in a Co-60 experimental four sources chamber (Precisa 22; Graviner Manufacturing Company Ltd, Gosport, UK), reaching a total activity of $105 \mathrm{TBq}(2.84 \mathrm{kCi})$. The absorbed doses were measured by standard dosimeters (Batch X; Amber Perspex Harwell, Didcot, UK). Doses after irradiation, dose rates and dose uniformity ratios $\left(D_{\max } / D_{\min }\right) \quad$ were: $1.1 \pm 0.1 \mathrm{kGy}, 2.4 \pm 0.2 \mathrm{kGy}$ and $5.4 \pm 0.2 \mathrm{kGy} ; 1.4 \mathrm{kGy} / \mathrm{h}$ and 1.3 , respectively.

Electron bean irradiation was carried out in the same facility indicated above, using LINAC equipment (GE Saturne 41) with an electron beam of $10 \mathrm{MeV}$ (pulse duration: $4 \mu \mathrm{s}$; pulse frequency: $20-60 \mathrm{~Hz}$ ), in a steel metal tray with four layers of acrylic $(1 \mathrm{~cm}) 60 \mathrm{~cm}$ away from the beam exit, at an average dose rate of $0.5 \mathrm{kGy} / \mathrm{min}$. The absorbed doses were $0.9 \pm 0.1 \mathrm{kGy}, 2.0 \pm 0.1 \mathrm{kGy}$ and $4.6 \pm 0.2 \mathrm{kGy}$, with an uncertainty of $7 \%$ for the first dose and $10 \%$ for the other two doses (Amber FWT-60 dosimeters; Far West Technology, Inc., Goleta, CA). For simplicity, the irradiation doses were indicated in the text, tables and graphs as 1, 2 and $5 \mathrm{kGy}$.

Groups corresponding to each irradiation dose were divided in three subgroups (three mushrooms: subgroup 1 was promptly analyzed (0 days), subgroup 2 was stored 4 days at $5{ }^{\circ} \mathrm{C}$ and subgroup 3 was stored 8 days under the same conditions. Considering the typical shelflife time of mushrooms, there was no need to assay at longer time intervals. Before being analyzed, all samples were lyophilized (FreeZone 4.5 model 7750031, Labconco, Kansas City, MO), powdered (20 mesh) and mixed to obtain homogeneous samples.

\subsection{Nutritional value}

Carbohydrates, fat, protein, ash and moisture were determined according to AOAC procedures (AOAC, 2016); a conversion factor of 4.38 was used in the macro-Kjeldahl determination of proteins; the Soxhlet extraction of fat was performed using petroleum ether; a temperature of $600 \pm 15^{\circ} \mathrm{C}$ was set in the muffle for ash determination; total carbohydrates were calculated as $100-\left(g_{\text {moisture }}+g_{\text {protein }}\right.$ $\left.+g_{\text {fat }}+g_{\text {ash }}\right)$. The energy value was calculated as: energy $($ kcal $)=4 \times\left(g_{\text {protein }}+g_{\text {carbohydrates }}\right)+9 \times\left(g_{\text {fat }}\right)$.

\subsection{Chemical composition}

Free sugars: Free sugars were analyzed by HPLC (Knauer, Smartline System 1000) using a refraction index detector (RI, Knauer, Berlin, Germany) and an Eurospher 100-5 $\mathrm{NH}_{2}$ column ( $5 \mu \mathrm{m}, 250 \times 4.6 \mathrm{~mm}$; Knauer, Berlin, Germany), at $35^{\circ} \mathrm{C}$. The mobile phase consisted of a mixture of acetonitrile/water (70:30, $v / v)$, maintaining a $1 \mathrm{~mL} / \mathrm{min}$ flow. Sugars were identified by comparing retention times of standard compounds and quantified using the RI signal based on the internal standard (IS, raffinose). Data were analyzed using Clarity 2.4 software (DataApex, Podohradska, Czech Republic); results were given as g/ $100 \mathrm{~g}$ dry weight $(\mathrm{dw})$.

Organic acids: Organic acids were analyzed in an ultrafast liquid chromatograph (UFLC; Shimadzu 20A series, Shimadzu Cooperation, Kyoto, Japan), using a photodiode array detector (PDA) with $215 \mathrm{~nm}$ as the preferred wavelength (Barros, Pereira, \& Ferreira, 2013). Compounds were separated in a SphereClone (Phenomenex, Torrance, CA) reverse-phase $\mathrm{C}_{18}$ column $\left(5 \mu \mathrm{m}, 250 \times 4.6 \mathrm{~mm}\right.$ i.d.), at $35^{\circ} \mathrm{C}$. A sulfuric acid solution $(3.6 \mathrm{mM}$ ) running at $0.8 \mathrm{~mL} / \mathrm{min}$ was used as mobile phase. Organic acids were quantified, comparing their peaks areas with commercial standards. Results were processed using LabSolutions Multi LC-PDA software (Shimadzu Corporation, Kyoto, Japan); results were expressed in $\mathrm{g} / 100 \mathrm{~g} \mathrm{dw}$.

Fatty acids: Fatty acids were characterized (after Soxhlet extraction and derivatization) by gas chromatography with flame ionization detection (GC-FID) at $260^{\circ} \mathrm{C}$, using a DANI model GC 1000 instrument equipped with a split/splitless injector and a Zebron Kame column $\left(30 \mathrm{~m} \times 0.25 \mathrm{~mm} \mathrm{ID} \times 0.20 \mu \mathrm{m} \mathrm{d}_{\mathrm{f}}\right.$, Phenomenex, Torrance, CA). The oven was set at an initial temperature of $100^{\circ} \mathrm{C}$, held for $2 \mathrm{~min}$, followed by a $10^{\circ} \mathrm{C} / \mathrm{min}$ ramp to $140{ }^{\circ} \mathrm{C}, 3{ }^{\circ} \mathrm{C} / \mathrm{min}$ ramp to $190^{\circ} \mathrm{C}, 30^{\circ} \mathrm{C} /$ min ramp to $260^{\circ} \mathrm{C}$ and held for $2 \mathrm{~min}$. The carrier gas (hydrogen) was maintained at a $1.1 \mathrm{~mL} / \mathrm{min}$ flow, and samples were injected in split injection (1:50) mode at $250^{\circ} \mathrm{C}$. Fatty acids were identified by comparing the relative retention times of fatty acid methyl esters (FAME) peaks from samples with commercial standards. Results were processed using Clarity DataApex 4.0 Software (DataApex, Prague, Czech Republic) and expressed as a relative percentage of each fatty acid.

Tocopherols: Tocopherols were extracted after adding tocol (Matreya, Pleasant Gap, PA) to mushroom samples (Reis, Barros, Martins, \& Ferreira, 2012). The analysis was carried out by HPLC (Knauer, Smartline System 1000, Berlin, Germany) using a fluorescence detector (FP-2020; Jasco, Easton, MD), programmed for excitation at $290 \mathrm{~nm}$ and emission at $330 \mathrm{~nm}$. A Polyamide II normal-phase column ( $250 \times 4.6 \mathrm{~mm}$; YMC Waters) operating at $35{ }^{\circ} \mathrm{C}$ was used to resolve the compounds. The mobile phase consisted of an $n$-hexane/ethyl acetate mixture $(70: 30, v / v)$ at $1 \mathrm{~mL} / \mathrm{min}$. Tocopherols were identified by comparing chromatographic data with commercial standards and quantified based on the IS (tocol). Data were analyzed by Clarity 2.4 software (DataApex, Prague, Czech Republic) and results were expressed in $\mu \mathrm{g} / 100 \mathrm{~g} \mathrm{dw}$.

Ergosterol: Samples were vortex-extracted (1 min; LBX V05 series, Barcelona, Spain) with $n$-hexane (using a 1:30 solid:liquid ratio) and further centrifuged ( $4000 \mathrm{rpm}, 10 \mathrm{~min}$; K24OR refrigerated centrifuge; Centurion Scientific Limited, Chichester, UK) twice (the supernatant was removed between each step). The combined supernatants were dried under a nitrogen stream and dissolved in $\mathrm{MeOH}(1 \mathrm{~mL}$ ) (Guan et al., 2016). The identification and quantification of ergosterol was performed according to the procedure descried by Barreira, Oliveira, and Ferreira (2014), using an HPLC (Knauer, Smartline System 1000, Berlin, Germany), coupled to a UV ( $280 \mathrm{~nm}$ as preferred wavelength) detector (Knauer Smartline 2500). The chromatographic separation was performed through an Inertsil 100A ODS-3 reverse-phase column 
( $5 \mu \mathrm{m}, 250 \times 4.6 \mathrm{~mm}$; BGB Analytik AG, Boeckten, Switzerland), at $35^{\circ} \mathrm{C}$. The mobile phase was a mixture of methanol:acetonitrile $(70: 30$, $v / v$ ), fed at $1 \mathrm{~mL} / \mathrm{min}$. Data were analyzed using Clarity 2.4 Software (DataApex, Podohradska, Czech Republic) and ergosterol (Sigma-Aldrich, St. Louis, MO) was quantified using a calibration curve obtained with a commercial standard. The results were expressed in $\mathrm{mg} / 100 \mathrm{~g}$ of mushroom (dw).

\subsection{Statistical analysis}

All statistical tests were applied considering a 5\% significance level (SPSS, v. 22.0; IBM Corp., Armonk, NY). Data were expressed as mean \pm standard deviation, presenting the significant numbers in agreement with the magnitude of the corresponding standard deviation.

The results were compared through analysis of variance (ANOVA) with type III sums of squares, performed using the general linear model (GLM) procedure. The parameters measured in A. bisporus Portobello samples (dependent variables) were analyzed using 2-way ANOVA, with "irradiation dose" (ID) and "storage time" (ST) as the statistical factors. Each table was divided in two sections: the top part corresponds to the gamma irradiation study, while the bottom section corresponds to the electron beam irradiation study. The statistical interaction among the two factors was also verified in both cases.

In addition, linear discriminant analysis (LDA) was used to compare gamma and electron beam irradiation as a whole, as well as to check the main parametric changes occurring throughout time. The stepwise technique was selected and the Wilks' $\lambda$ test was applied, considering an $F$-value of 3.84 for entering a variable, and 2.71 for variable removal. A leaving-one-out cross validation procedure was carried out to verify the model performance.

\section{Results and discussion}

Results obtained in all analytical assays were divided in samples treated by gamma irradiation (first half of each table) and samples treated by electron beam irradiation (second half of each table), to better understand their effects throughout time. In each case, the variability of results resulted from combining two distinct factors: irradiation dose (ID), with the levels $0,1,2$ and $5 \mathrm{kGy}$ and storage time (ST), with the levels 0,4 and 8 days. In such cases, the interaction among factors (ID $\times$ ST) was also analyzed, in order to verify if changes potentially induced by one factor are dissimilar within each level of the other.

In the present study, and independently of the analyzed parameter, the interaction was significant in all cases, not allowing to present the statistical classification that resulted from the performed multiple comparison test (Tukey's HSD test). Accordingly, the identifiable tendencies observed for each parameter were obtained from the estimated marginal mean (EMM) plots that were generated in the GLM analysis.

In what concerns nutritional composition (Table 1), gamma irradiation (GI) caused a higher number of significant changes than ST, which had a significant effect only on protein and carbohydrate content. In each case, no unequivocal trends could be obtained from the EMM plots. In fact, the values quantified in each case are highly similar, with moisture as the major component $(89 \%)$. This high water percentage could increase the release of primary free radicals (hydroxyl, hydrogen atoms and hydrated electrons) as a result of irradiation, thereby justifying the need to study several different chemical parameters, as performed in this work.

On a dry weight (dw) basis, carbohydrates were the main (64-65 g/ $100 \mathrm{~g} \mathrm{dw}$ ) component, followed by protein (23.2-24.5 g/100 g dw), ash (9.2-9.9 g/100 g dw) and fat $(1.7-1.8 \mathrm{~g} / 100 \mathrm{~g} \mathrm{dw})$.

The results obtained in electron beam (EB) irradiated samples were similar. At least one EB dose caused a significant change in all nutritional parameters, while ST only affected protein and carbohydrate content. Despite the detected significant differences, the EMM plots showed that the only observed overall tendency was the higher protein content in samples irradiated with $5 \mathrm{kGy}$. All in all, it seems obvious that neither GI, nor EB, exert any remarkably negative effect over the nutritional parameters of stored (up to 8 days) Portobello samples, which is in agreement with the results obtained in other mushroom species (Fernandes et al., 2014b, 2015, 2016).

Moving on to the polar compound profiles (Table 2), herein represented by organic acids and sugars, which are important indicators of reliable preservation conditions (Barreira, Pereira, Oliveira, \& Ferreira, 2010), several significant differences were detected. In fact, nearly all parameters (except for mannitol and grouped sugars) showed a significantly different value for at least one GI dose or a specific ST. However, these differences corresponded to overall trends only in the case of malic acid (higher in samples irradiated with GI at $5 \mathrm{kGy}$ and lower in non-stored samples) and grouped organic acids (higher in samples stored for 8 days).

In the case of Portobello treated with EB irradiation, the significant differences were detected in a higher number of parameters, since this effect was observed in all cases except trehalose content $(p=0.051)$. Furthermore, several tendencies could be obtained from the corresponding EMM plots: non-irradiated samples showed lower contents in malic acid $(0.5 \mathrm{~g} / 100 \mathrm{~g} \mathrm{dw})$ and grouped organic acids $(2.7 \mathrm{~g} / 100 \mathrm{~g}$ $\mathrm{dw})$, but higher concentration of mannitol $(38 \mathrm{~g} / 100 \mathrm{~g} \mathrm{dw})$ and grouped sugars (41 g/100 $\mathrm{g} \mathrm{dw}$ ); samples irradiated with $2 \mathrm{kGy}$ gave the highest value in quinic acid $(1.0 \mathrm{~g} / 100 \mathrm{~g} \mathrm{dw})$, which showed the lowest value $(0.8 \mathrm{~g} / 100 \mathrm{~g} \mathrm{dw})$ in non-stored samples, similarly to malic acid $(1.6 \mathrm{~g} /$ $100 \mathrm{~g} \mathrm{dw})$ and grouped organic acids $(3.0 \mathrm{~g} / 100 \mathrm{~g} \mathrm{dw})$. The low-extent changes detected in sugars and organic acids are also in agreement with previous reports describing the effects of irradiation in related mushroom species (Fernandes et al., 2015, 2016).

In what concerns lipophilic compounds, the studied molecules were fatty acids, tocopherols and ergosterol. Fatty acids are also considered as good indicators of suitable shelf-life conditions (Barreira et al., 2014; Pereira et al., 2016), while tocopherols and ergosterol are well known for their bioactivity, particularly antioxidant and hypocholesterolemic effects, respectively. In addition to those presented in Table 3, other fatty acids were quantified, specifically C6:0, C11:0, C12:0, C13:0, C14:0, C15:0, C16:1, C17:0, cis-C18:1n-9, trans-C18:2n-6, $\mathrm{C} 18: 3 n-3, \mathrm{C} 20: 1, \mathrm{C} 20: 2, \mathrm{C} 21: 0$ and C23:0, but in percentages below $0.5 \%$ (however, all were used in the linear discriminant analysis discussed in the next section).

Gamma-irradiated samples presented statistical differences in MUFA and $\beta$-tocopherol in result of GI dose and in $\alpha$-tocopherol and ergosterol, regarding ST effect. Some of these differences corresponded to overall trends observable in the EMM plots, namely higher percentages of C16:0 (8.6\%) in samples irradiated with $5 \mathrm{kGy}$, lower C20:0 $(1.6 \%)$ in the same samples and lower C18:0 (3.4\%) in non-irradiated ones. Non-stored samples, in turn, showed lower percentages of C20:0 (1.6\%) and lower $\beta$-tocopherol content $(9.9 \mu \mathrm{g} / 100 \mathrm{~g} \mathrm{dw})$, while the lowest percentages of cis-C18:2n-6 (78.6\%) and PUFA (79\%) were measured in samples stored for 8 days, which, on the other hand, gave the highest SFA percentage (20.1\%).

In the case of EB-irradiated Portobello (Table 3), most parameters presented also significant differences, except C18:0 and $\beta$-tocopherol regarding EB effect, and MUFA, $\alpha$-tocopherol and $\beta$-tocopherol, in ST. From the corresponding EMM plots, it was possible to conclude that samples irradiated with $1 \mathrm{kGy}$ presented higher percentages of cisC18:2n - 6 (78.9\%) and PUFA (79.4\%) and lower percentages of SFA (19.5\%), while non-irradiated ones showed the lowest content $(1.8 \%)$ of C20:0. In ST, it was only possible to verify that 8 days stored samples showed the lowest percentage of cis-C18:2n- 6 (78.1\%).

The slight differences in lipophilic compounds (which are prone to be oxidized) were previously reported in mushrooms (Fernandes et al., 2016) and may result from autoxidation processes, since Portobello samples were not stored in oxygen-free conditions. Since the occurrence of this important phenomenon might affect the sensorial quality of 
Table 1

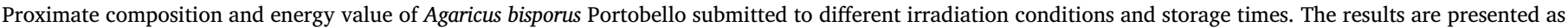
mean \pm SD. ${ }^{1}$

\begin{tabular}{|c|c|c|c|c|c|c|c|}
\hline & & Moisture (g/100 g fw) & Fat $(g / 100 \mathrm{~g} \mathrm{dw})$ & Proteins $(\mathrm{g} / 100 \mathrm{~g} \mathrm{dw})$ & Ash $(g / 100 \mathrm{~g} \mathrm{dw})$ & Carbohydrates (g/100g dw) & $\begin{array}{l}\text { Energy } \\
(\mathrm{kcal} / 100 \mathrm{~g} \mathrm{dw})\end{array}$ \\
\hline & & \multicolumn{6}{|l|}{ Gamma irradiation (GI) } \\
\hline \multirow[t]{5}{*}{ GI } & 0 kGy & $89 \pm 2$ & $1.8 \pm 0.1$ & $24.2 \pm 0.5$ & $9.2 \pm 0.5$ & $65 \pm 1$ & $372 \pm 2$ \\
\hline & $1 \mathrm{kGy}$ & $89 \pm 1$ & $1.7 \pm 0.1$ & $23.2 \pm 0.4$ & $9.9 \pm 0.5$ & $65 \pm 1$ & $369 \pm 2$ \\
\hline & $2 \mathrm{kGy}$ & $89 \pm 1$ & $1.7 \pm 0.1$ & $23.2 \pm 0.4$ & $9.9 \pm 0.5$ & $65 \pm 1$ & $369 \pm 3$ \\
\hline & $5 \mathrm{kGy}$ & $89 \pm 1$ & $1.8 \pm 0.1$ & $24.5 \pm 0.4$ & $9.2 \pm 0.4$ & $64 \pm 1$ & $372 \pm 2$ \\
\hline & ANOVA $p$-value $(n=27)^{2}$ & 0.090 & $<0.001$ & $<0.001$ & $<0.001$ & 0.003 & $<0.001$ \\
\hline \multirow[t]{4}{*}{ ST } & 0 days & $89 \pm 1$ & $1.8 \pm 0.1$ & $24.3 \pm 0.5$ & $9.6 \pm 0.5$ & $64 \pm 1$ & $370 \pm 4$ \\
\hline & 4 days & $89 \pm 1$ & $1.8 \pm 0.1$ & $23.5 \pm 0.5$ & $9.5 \pm 0.5$ & $65 \pm 1$ & $371 \pm 3$ \\
\hline & 8 days & $89 \pm 1$ & $1.7 \pm 0.1$ & $23.5 \pm 0.5$ & $9.6 \pm 0.3$ & $65 \pm 1$ & $370 \pm 1$ \\
\hline & ANOVA $p$-value $(n=36)^{3}$ & 0.074 & 0.105 & $<0.001$ & 0.425 & $<0.001$ & 0.464 \\
\hline \multicolumn{2}{|c|}{ GI $\times$ ST $p$-value $(n=108)^{4}$} & $<0.001$ & $<0.001$ & $<0.001$ & $<0.001$ & $<0.001$ & $<0.001$ \\
\hline & & \multicolumn{6}{|c|}{ Electron beam irradiation (EB) } \\
\hline \multirow[t]{5}{*}{ EB } & 0 kGy & $90 \pm 1$ & $1.8 \pm 0.1$ & $24.7 \pm 0.5$ & $9.2 \pm 0.4$ & $64 \pm 1$ & $372 \pm 2$ \\
\hline & $1 \mathrm{kGy}$ & $89 \pm 1$ & $1.7 \pm 0.1$ & $23.6 \pm 0.4$ & $9.8 \pm 0.4$ & $65 \pm 1$ & $369 \pm 2$ \\
\hline & $2 \mathrm{kGy}$ & $90 \pm 1$ & $1.7 \pm 0.1$ & $23.6 \pm 0.4$ & $9.8 \pm 0.5$ & $65 \pm 1$ & $369 \pm 3$ \\
\hline & $5 \mathrm{kGy}$ & $89 \pm 1$ & $1.8 \pm 0.1$ & $24.9 \pm 0.5$ & $9.2 \pm 0.4$ & $64 \pm 1$ & $372 \pm 2$ \\
\hline & ANOVA $p$-value $(n=27)^{2}$ & $<0.001$ & $<0.001$ & $<0.001$ & $<0.001$ & 0.001 & $<0.001$ \\
\hline \multirow[t]{5}{*}{ ST } & 0 days & $89 \pm 1$ & $1.8 \pm 0.1$ & $24.9 \pm 0.5$ & $9.6 \pm 0.5$ & $64 \pm 1$ & $370 \pm 3$ \\
\hline & 4 days & $90 \pm 1$ & $1.8 \pm 0.1$ & $23.7 \pm 0.4$ & $9.4 \pm 0.5$ & $65 \pm 1$ & $371 \pm 3$ \\
\hline & 8 days & $89 \pm 1$ & $1.7 \pm 0.1$ & $24.0 \pm 0.4$ & $9.6 \pm 0.2$ & $65 \pm 1$ & $370 \pm 1$ \\
\hline & ANOVA $p$-value $(n=36)^{3}$ & 0.518 & 0.237 & $<0.001$ & 0.176 & $<0.001$ & 0.217 \\
\hline & $\mathrm{EB} \times \mathrm{ST} p$-value $(n=108)^{4}$ & 0.003 & $<0.001$ & $<0.001$ & $<0.001$ & $<0.001$ & $<0.001$ \\
\hline
\end{tabular}

1 Results are reported as mean values of each irradiation dose (GI or EB), aggregating results from 0, 4 and 8 days, and mean values of ST, combining all irradiation doses (from GI or EB).

${ }^{2}$ If $p<0.05$, the corresponding parameter presented a significantly different value for at least one GI or EB.

${ }^{3}$ If $p<0.05$, the corresponding parameter had a significant difference for at least one of the time intervals.

4 The interaction among factors was significant in all cases; thereby the statistical classification could not be indicated.

Table 2

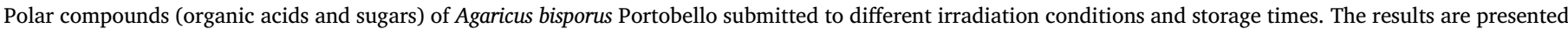
as mean \pm SD. $^{1}$

\begin{tabular}{|c|c|c|c|c|c|c|c|c|c|}
\hline & & \multicolumn{4}{|c|}{ Sugars $(\mathrm{g} / 100 \mathrm{~g} \mathrm{dw})$} & \multicolumn{4}{|c|}{ Organic acids (g/100 g dw) } \\
\hline & & Fructose & Mannitol & Trehalose & Total & Oxalic acid & Quinic acid & Malic acid & Total \\
\hline & & \multicolumn{8}{|c|}{ Gamma irradiation (GI) } \\
\hline \multirow[t]{5}{*}{ GI } & $0 \mathrm{kGy}$ & $0.6 \pm 0.1$ & $36 \pm 2$ & $1.6 \pm 0.4$ & $38 \pm 3$ & $0.7 \pm 0.1$ & $0.8 \pm 0.1$ & $1.5 \pm 0.1$ & $3.0 \pm 0.3$ \\
\hline & $1 \mathrm{kGy}$ & $0.7 \pm 0.2$ & $36 \pm 3$ & $1.4 \pm 0.3$ & $38 \pm 2$ & $0.7 \pm 0.1$ & $0.9 \pm 0.1$ & $1.6 \pm 0.1$ & $3.2 \pm 0.3$ \\
\hline & $2 \mathrm{kGy}$ & $0.6 \pm 0.1$ & $36 \pm 3$ & $1.2 \pm 0.2$ & $37 \pm 3$ & $0.6 \pm 0.1$ & $0.9 \pm 0.1$ & $1.5 \pm 0.1$ & $3.1 \pm 0.1$ \\
\hline & $5 \mathrm{kGy}$ & $0.6 \pm 0.1$ & $35 \pm 3$ & $1.5 \pm 0.3$ & $37 \pm 2$ & $0.6 \pm 0.1$ & $0.8 \pm 0.1$ & $1.7 \pm 0.1$ & $3.2 \pm 0.2$ \\
\hline & ANOVA $p$-value $(n=27)^{2}$ & 0.007 & 0.712 & 0.001 & 0.559 & 0.025 & $<0.001$ & $<0.001$ & 0.012 \\
\hline \multirow[t]{4}{*}{ ST } & 0 days & $0.5 \pm 0.1$ & $36 \pm 3$ & $1.5 \pm 0.2$ & $38 \pm 3$ & $0.6 \pm 0.1$ & $0.8 \pm 0.1$ & $1.5 \pm 0.1$ & $2.9 \pm 0.2$ \\
\hline & 4 days & $0.6 \pm 0.1$ & $36 \pm 2$ & $1.2 \pm 0.2$ & $37 \pm 2$ & $0.6 \pm 0.1$ & $0.9 \pm 0.1$ & $1.6 \pm 0.1$ & $3.1 \pm 0.1$ \\
\hline & 8 days & $0.7 \pm 0.2$ & $36 \pm 3$ & $1.5 \pm 0.4$ & $38 \pm 3$ & $0.8 \pm 0.1$ & $0.9 \pm 0.1$ & $1.6 \pm 0.1$ & $3.4 \pm 0.1$ \\
\hline & ANOVA $p$-value $(n=36)^{3}$ & $<0.001$ & 0.976 & $<0.001$ & 0.700 & $<0.001$ & $<0.001$ & $<0.001$ & $<0.001$ \\
\hline \multicolumn{2}{|c|}{ GI $\times$ ST $p$-value $(n=108)^{4}$} & $<0.001$ & $<0.001$ & $<0.001$ & $<0.001$ & $<0.001$ & $<0.001$ & $<0.001$ & $<0.001$ \\
\hline & & \multicolumn{8}{|c|}{ Electron beam irradiation (EB) } \\
\hline \multirow[t]{5}{*}{ EB } & $0 \mathrm{kGy}$ & $0.8 \pm 0.2$ & $38 \pm 2$ & $1.8 \pm 0.5$ & $41 \pm 3$ & $0.5 \pm 0.1$ & $0.8 \pm 0.1$ & $1.3 \pm 0.1$ & $2.7 \pm 0.1$ \\
\hline & $1 \mathrm{kGy}$ & $0.7 \pm 0.2$ & $33 \pm 2$ & $1.5 \pm 0.4$ & $35 \pm 2$ & $0.6 \pm 0.1$ & $0.9 \pm 0.1$ & $1.7 \pm 0.1$ & $3.2 \pm 0.1$ \\
\hline & $2 \mathrm{kGy}$ & $0.6 \pm 0.1$ & $31 \pm 7$ & $1.5 \pm 0.2$ & $33 \pm 7$ & $0.6 \pm 0.1$ & $1.0 \pm 0.1$ & $1.8 \pm 0.1$ & $3.4 \pm 0.2$ \\
\hline & $5 \mathrm{kGy}$ & $0.7 \pm 0.1$ & $34 \pm 2$ & $1.7 \pm 0.2$ & $36 \pm 2$ & $0.6 \pm 0.1$ & $0.9 \pm 0.1$ & $1.9 \pm 0.1$ & $3.4 \pm 0.1$ \\
\hline & ANOVA $p$-value $(n=27)^{2}$ & $<0.001$ & $<0.001$ & 0.051 & $<0.001$ & $<0.001$ & $<0.001$ & $<0.001$ & $<0.001$ \\
\hline \multirow[t]{4}{*}{ ST } & 0 days & $0.7 \pm 0.1$ & $36 \pm 3$ & $2.0 \pm 0.5$ & $39 \pm 4$ & $0.6 \pm 0.1$ & $0.8 \pm 0.1$ & $1.6 \pm 0.2$ & $3.0 \pm 0.3$ \\
\hline & 4 days & $0.8 \pm 0.1$ & $34 \pm 1$ & $1.4 \pm 0.1$ & $37 \pm 1$ & $0.6 \pm 0.1$ & $0.9 \pm 0.1$ & $1.7 \pm 0.2$ & $3.2 \pm 0.3$ \\
\hline & 8 days & $0.5 \pm 0.1$ & $32 \pm 7$ & $1.5 \pm 0.3$ & $34 \pm 7$ & $0.6 \pm 0.1$ & $1.0 \pm 0.1$ & $1.7 \pm 0.2$ & $3.3 \pm 0.3$ \\
\hline & ANOVA $p$-value $(n=36)^{3}$ & $<0.001$ & $<0.001$ & $<0.001$ & $<0.001$ & 0.022 & $<0.001$ & 0.063 & 0.001 \\
\hline \multicolumn{2}{|c|}{$\mathrm{EB} \times \mathrm{ST} p$-value $(n=108)^{4}$} & 0.003 & $<0.001$ & $<0.001$ & $<0.001$ & $<0.001$ & $<0.001$ & 0.011 & 0.005 \\
\hline
\end{tabular}

1 Results are reported as mean values of each irradiation dose (GI or EB), aggregating results from 0 , 4 and 8 days, and mean values of ST, combining all irradiation doses (from GI or EB).

${ }^{2}$ If $p<0.05$, the corresponding parameter presented a significantly different value for at least one GI or EB.

${ }^{3}$ If $p<0.05$, the corresponding parameter had a significant difference for at least one of the time intervals.

4 The interaction among factors was significant in all cases; thereby the statistical classification could not be indicated. 


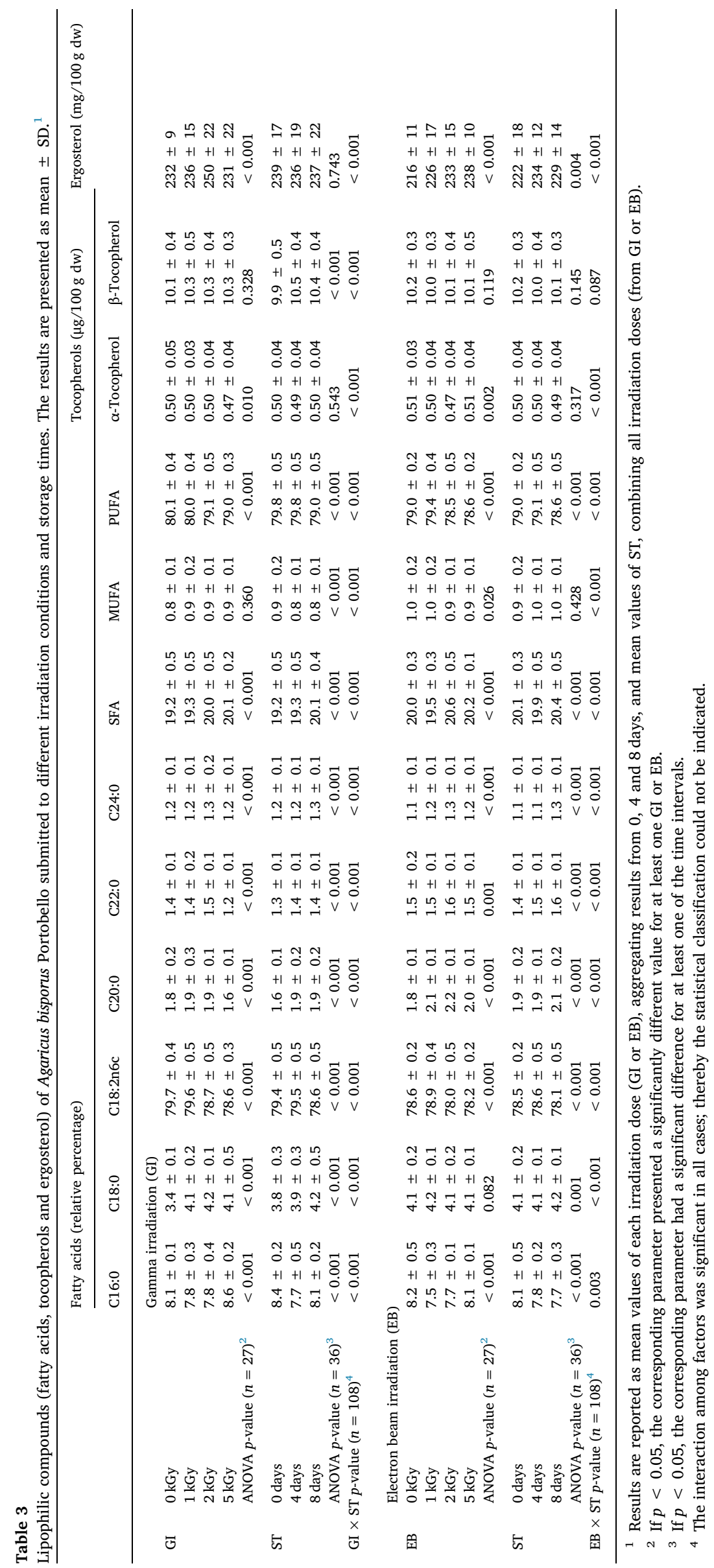


mushrooms, it is worth mentioning, however, that the results obtained herein seem to indicate that lipid oxidation occurred to a minor extent (as indicated by the maintenance of percentages of fatty acids more prone to be oxidized).

All in all, irradiation seem to be a suitable conservation technique, owing to its capacity to maintain the chemical profiles of this mushroom species for extended shelf-life periods. In what concerns its application at industrial level, the effective cost should be considered. The high price of the irradiation equipment might be considered as a strong constraint, but it should also be borne in mind that the operational costs (e.g., product transportation) are much less than other presently available conservation technologies.

\section{Linear discriminant analysis}

According to the analysis of results described in the previous section, GI and EB seemed to have dissimilar effects over the chemical composition of stored Portobello mushrooms. Therefore, we hypothesized that the effects produced by each irradiation type could be different enough to discriminate them. To verify this hypothesis, a linear discriminant analysis (LDA) was applied to the complete set of results, without separating those obtained with each irradiation type (as presented in Tables 1-3).

The first three discriminant functions of the obtained model included $98.8 \%$ (first function: $96.5 \%$; second function: $1.5 \%$; third function: $0.8 \%$ ) of the observed variance (Fig. 1). Among the 42 variables (corresponding to each analyzed parameter) included in the LDA, only 12 (moisture, protein, mannitol, grouped sugars, quinic acid, grouped organic acids, C16:1, C20:0, C20:2, SFA, PUFA and ergosterol) were considered as not having discriminant ability, therefore indicating a high dissimilarity among samples treated with GI or EB.

The most obvious separation effect observed in Fig. 1 is the location of markers corresponding to EB at the positive end of the corresponding axis, while GI markers were placed at the opposite end of the same axis. This separation is more relevant if we consider the percentage of variability that was explained by function $1(96.5 \%)$; indeed, this is a clear indicator of the high dissimilarity among GI-irradiated and EBirradiated samples of Portobello. Taking into account the correlations among functions and variables coefficients, the parameters with highest contribution to the separation resulting from function 1 were grouped sugars $(37.8 \mathrm{~g} / 100 \mathrm{~g} \mathrm{dw}$ in GI-irradiated samples and $36.4 \mathrm{~g} / 100 \mathrm{~g} \mathrm{dw}$ in EB-irradiated samples) and ergosterol $(237 \mathrm{mg} / 100 \mathrm{~g} \mathrm{dw}$ in GI-

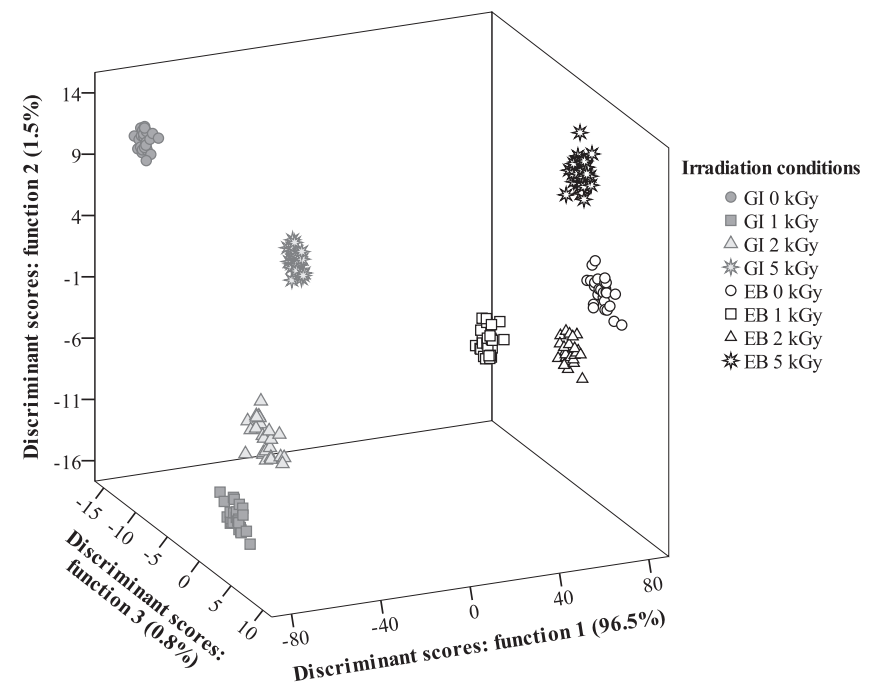

Fig. 1. Three-dimensional distribution of gamma and electron beam irradiation markers according to the canonical discriminant functions coefficients defined from all parameters analyzed in Agaricus bisporus Portobello. irradiated samples and $228 \mathrm{mg} / 100 \mathrm{~g} \mathrm{dw}$ in EB-irradiated samples), indicating that these are the two variables with highest changes between GI and EB.

Another interesting observation results from the fact that, in addition to the complete individualization of markers corresponding to each irradiation technology, it was also possible to discriminate the irradiation doses assayed within GI and EB. In fact, function 2 divided GI doses in two groups: a first one integrating 0 and $5 \mathrm{kGy}$ markers, and a second one including 1 and $2 \mathrm{kGy}$ markers. The greatest differences among these two groups were related with protein (higher in non-irradiated samples and those irradiated with $5 \mathrm{kGy}$ ) and C20:2 (higher in samples irradiated with 1 or $2 \mathrm{kGy}$ ). In the case of EB-irradiated samples, the four dose levels were also divided in a similar way ( 0 and $5 \mathrm{kGy}$ on the positive side, 1 and $2 \mathrm{kGy}$ on the negative side), mainly due to the higher percentages of C20:0 in samples irradiated with 1 or $2 \mathrm{kGy}$, and also their lower protein content.

Function 3, in turn, was mostly correlated with moisture and C16:1, contributing to separate markers from non-irradiated samples and those of samples irradiated with $5 \mathrm{kGy}$, concerning GI treatment, and samples irradiated with 1 and $2 \mathrm{kGy}$ for EB-irradiated ones.

In addition to verify the parameters with highest changes within each irradiation type, we also intended to check which parameters were more affected by storage. In this second LDA, the two defined discriminant functions included $100.0 \%$ (first function: $76.8 \%$; second function: $23.2 \%$ ) of the observed variance (Fig. 2). Among the 42 variables included in the LDA, 16 (moisture, fat, protein, ash, energy, oxalic acid, malic acid, ergosterol, fructose, grouped sugars, $\alpha$-tocopherol, $\beta$-tocopherol, grouped tocopherols, C12:0, C17:0, transC18:2n - 6, C20:0, C20:2, C22:0, C23:0, MUFA and PUFA) were not selected as being discriminant, indicating that those were the least affected by storage.

As it might be easily observed in Fig. 2, function 1 separates mainly markers corresponding to non-stored samples from those belonging to samples stored for 8 days. The variables more correlated with function 1 were quinic acid, organic acids, and C24:0 (all higher in 8 days-stored samples). Function 2, on the other hand, projected the markers corresponding to 4-days-stored samples away from those belonging to nonstored samples and those stored for 8 days. The variables more correlated with this second function were carbohydrates (higher after 4 days of storage) and C16:0 (lower after 4 days of storage).

In both performed LDAs, the classification performance was $100 \%$

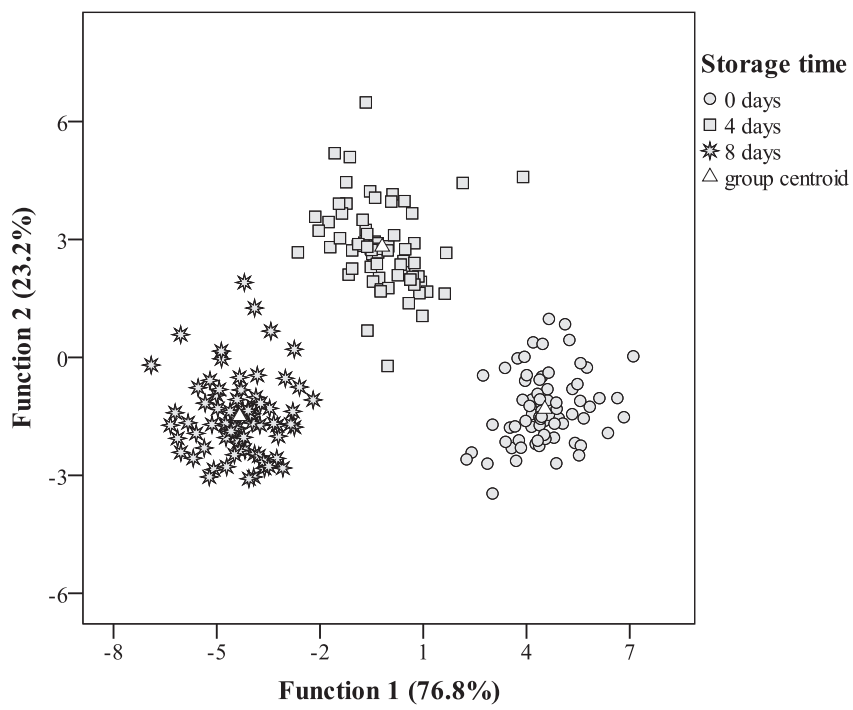

Fig. 2. Two-dimensional storage time markers according to the canonical discriminant functions coefficients defined from all parameters analyzed in Agaricus bisporus Portobello. 
accurate, both for original grouped cases, as well as for the cross-validated grouped cases.

\section{Conclusion}

Overall, it was possible to conclude that the effects of each irradiation technology are more distinctive than those caused by different doses of the same irradiation type. When directly comparing gamma irradiation and electron beam irradiations, independently of the used dose, it could be concluded that gamma irradiation allowed higher contents in sugars and ergosterol. In addition, the $5 \mathrm{kGy}$ dose, independently of irradiation type, tended to be associated with higher levels of protein. On the other hand, in what concerns the effect of storage time, it could be verified that GI and EB were effective in maintaining the chemical profiles of Portobello samples, except for quinic acid, grouped organic acids and some particular SFA. Accordingly, these technologies might represent effective preservation approaches for Portobello mushrooms.

\section{Declaration of interests}

None.

\section{Acknowledgements}

The authors are grateful to the Foundation for Science and Technology (FCT, Portugal) and FEDER under Programme PT2020 for financial support to CIMO (UID/AGR/00690/2013), C2TN (UID/Multi/ 04349/2013), L. Barros and J. Barreira contracts, and A. Fernandes post-doc grant (SFRH/BPD/114753/2016). This work is funded by the European Structural and Investment Funds (FEEI) through the Regional Operational Program North 2020, within the scope of Project Mobilizador ValorNatural ${ }^{\circledR}$; and to FEEI through the Rural Development Program (PDR2020), within the scope of Project MicoCoating (PDR2020-101-031472). This work was also developed within the Coordinated Research Project D61024 "Development of New Applications of Machine Generated Food Irradiation Technologies" financed by the International Atomic Energy Agency (IAEA).

\section{References}

Akram, K., \& Kwon, J. H. (2010). Food irradiation for mushrooms: A review. Journal of Applied Biological Chemistry, 53, 257-265.

AOAC. (2016). Official Methods of Analysis of AOAC International. Association of Official Analysis Chemists International (20th ed.).

Barreira, J. C. M., Oliveira, M. B. P. P., \& Ferreira, I. C. F. R. (2014). Development of a novel methodology for the analysis of ergosterol in mushrooms. Food Analytical Methods, 7(1), 217-223. https://doi.org/10.1007/s12161-013-9621-9.

Barreira, J. C. M., Pereira, J. A., Oliveira, M. B. P. P., \& Ferreira, I. C. F. R. (2010). Sugars profiles of different chestnut (Castanea sativa Mill.) and almond (Prunus dulcis) cultivars by HPLC-RI. Plant Foods for Human Nutrition, 65(1), 38-43. https://doi.org/10. 1007/s11130-009-0147-7

Barros, L., Pereira, C. \& Ferreira, I. C. F. R. (2013). Optimized analysis of organic acids in edible mushrooms from Portugal by ultra fast liquid chromatography and photodiode array detection. Food Analytical Methods, 6(1), 309-316. https://doi.org/10.1007/ s12161-012-9443-1.

Fernandes, Â. (2015). Radiação gama e por feixe de eletrões na preservação de cogumelos silvestres: efeito em parâmetros físico-químicos, nutricionais e bioativos. Faculdade de Farmácia, Universidade do Porto.

Fernandes, Â., Barreira, J. C. M., Antonio, A. L., Oliveira, M. B. P. P., Martins, A., \& Ferreira, I. C. F. R. (2014a). Combined effects of electron-beam irradiation and storage time on the chemical and antioxidant parameters of wild Macrolepiota procera dried samples. Food and Bioprocess Technology, 7, 1606-1617.

Fernandes, Â., Barreira, J. C. M., Antonio, A. L., Oliveira, M. B. P. P., Martins, A., \& Ferreira, I. C. F. R. (2014b). Feasibility of electron-beam irradiation to preserve wild dried mushrooms: Effects on chemical composition and antioxidant activity. Innovative Food Science and Emerging Technologies, 22, 158-166.

Fernandes, Â., Barreira, J. C. M., Antonio, A. L., Oliveira, M. B. P. P., Martins, A., \& Ferreira, I. C. F. R. (2016). Extended use of gamma irradiation in wild mushrooms conservation: Validation of $2 \mathrm{kGy}$ dose to preserve their chemical characteristics. LWT - Food Science and Technology, 67, 99-105.

Fernandes, Â., Barreira, J. C. M., Antonio, A. L., Rafalski, A., Oliveira, M. B. P. P., Martins, A., \& Ferreira, I. C. F. R. (2015). How does electron beam irradiation dose affect the chemical and antioxidant profiles of wild dried Amanita mushrooms? Food Chemistry, 182. https://doi.org/10.1016/j.foodchem.2015.03.012.

Guan, W., Zhang, J., Yan, R., Shao, S., Zhou, T., Lei, J., \& Wang, Z. (2016). Effects of UV-C treatment and cold storage on ergosterol and vitamin D2 contents in different parts of white and brown mushroom (Agaricus bisporus). Food Chemistry, 210, 129-134.

Jasinghe, V. J., \& Perera, C. O. (2006). Ultraviolet irradiation: The generator of vitamin D2 in edible mushrooms. Food Chemistry, 95, 638-643.

Jiang, T., Luo, S., Chen, Q., Shen, L., \& Ying, T. (2010). Effect of integrated application of gamma irradiation and modified atmosphere packaging on physicochemical and microbiological properties of shiitake mushroom (Lentinus edodes). Food Chemistry, 122, 761-767.

Lima, L. S. (2014). Radiação gama. Revista de Ciência Elementar, 2, 1-2.

Ma, L., Chen, H., Zhu, W., \& Wang, Z. (2013). Effect of different drying methods on physicochemical properties and antioxidant activities of polysaccharides extracted from mushroom Inonotus obliquus. Food Research International, 50, 633-640.

Pereira, E., Barros, L., Barreira, J. C. M., Carvalho, A. M., Antonio, A. L., \& Ferreira, I. C. F. R. (2016). Electron beam and gamma irradiation as feasible conservation technologies for wild Arenaria montana L.: Effects on chemical and antioxidant parameters. Innovative Food Science \& Emerging Technologies, 36, 269-276. https://doi.org/10. 1016/j.ifset.2016.07.012.

Raimundo, M. G. M., \& Beraldo, M. R. (2015). Gogumelos, variedades e receitas. São Paulo, Brasil: Coordenadoria de Desenvolvimento dos Agronegócios.

Reis, F. S., Barros, L., Martins, A., \& Ferreira, I. C. F. R. (2012). Chemical composition and nutritional value of the most widely appreciated cultivated mushrooms: An interspecies comparative study. Food and Chemical Toxicology, 50(2), 191-197. https:// doi.org/10.1016/j.fct.2011.10.056.

Reis, F. S., Martins, A., Vasconcelos, M. H., Morales, P., \& Ferreira, I. C. F. R. (2017). Functional foods based on extracts or compounds derived from mushrooms. Trends in Food Science \& Technology, 66, 48-62. https://doi.org/10.1016/j.tifs.2017.05.010.

Royse, D. J., Baars, J., \& Tan, Q. (2016). Edible and medicinal mushrooms: Technology and applications. New York: Wiley5-14.

Teichmann, A., Dutta, P. C., Staffas, A., \& Jägerstad, M. (2007). Sterol and vitamin D2 concentrations in cultivated and wild grown mushrooms: Effects of UV irradiation. LWT - Food Science and Technology, 40, 815-822.

Wani, A. M., Hussain, P. R., Meena, R. S., Dar, M. A., \& Mir, M. A. (2009). Effect of gamma irradiation and sulphitation treatments on keeping quality of white button mushroom Agaricus bisporus (J. Lge). International Journal of Food Science and Technology, 44, 967-973.Further reading

Fernandes, Â., Antonio, A. L., Oliveira, M. B. P. P., Martins, A., \& Ferreira, I. C. F. R. (2012). Effect of gamma and electron beam irradiation on the physico-chemical and nutritional properties of mushrooms: A review. Food Chemistry, 135, 641-650. 